\title{
HEART VALVES FROM PIGS AND THE PORCINE ENDOGENOUS RETROVIRUS: EXPERIMENTAL AND CLINICAL DATA TO ASSESS THE PROBABILITY OF PORCINE ENDOGENOUS RETROVIRUS INFECTION IN HUMAN SUBJECTS
}

\author{
A. K. Moza, MDa,c \\ H. Mertsching, $\mathrm{PhD}^{\mathrm{a}}$ \\ T. Herden ${ }^{\mathrm{a}}$ \\ A. Bader, MD ${ }^{\mathrm{a}, \mathrm{b}}$ \\ A. Haverich, $\mathrm{MD}^{\mathrm{a}, \mathrm{c}}$
}

Objective: Replacement of heart valves in human subjects has become a routine procedure in cardiac operations. We sought to investigate whether commercially available glutaraldehyde-fixed porcine heart valve prostheses cause porcine endogenous retrovirus infection in human subjects because recent studies revealed that human cells can be infected with porcine endogenous retrovirus.

Methods: Blood samples of 18 patients who underwent aortic or mitral valve replacement with porcine heart valves were collected 6 months to 3 years after operation and tested for porcine endogenous retrovirus by means of polymerase chain reaction and reverse transcriptase-polymerase chain reaction. In addition, we tried to trace porcine endogenous retrovirus in 3 commercially available, glutaraldehyde-fixed, porcine heart valves.

Results: Porcine endogenous retrovirus can be easily detected in native porcine heart valves and degrades completely within 1 week of fixation in glutaraldehyde. In all 3 commercially available porcine heart valves, no traces of porcine endogenous retrovirus were found. All blood samples showed negative test results for the porcine endogenous retrovirus genome.

Conclusion: Our results indicate that glutaraldehyde fixation of porcine heart valves reliably prevents cross-species transmission of porcine endogenous retrovirus. (J Thorac Cardiovasc Surg 2001;121:697-701)
$T^{o}$ amend the shortage of donor organs, investigators have directed much attention toward the possibility of xenotransplantation. ${ }^{1}$ In this context, however, there is much concern in the recent literature about possible transmission of a porcine endogenous retrovirus $(\mathrm{PERV})^{2}$ because many patients have been exposed to pig tissue and organs for various therapeutic reasons.

Patience, Takeuchi, and Weiss ${ }^{3}$ demonstrated the release of a C-type retrovirus from pig kidney cell lines (PK 15) capable of infecting human cells in vitro. Mitogenic stimulation of pig peripheral blood monocytes (PBMCs), as shown by Wilson and associates, ${ }^{4}$ produces a virus infectious to HEK 239 and HeLa cell lines. Further studies revealed at least 2 types of PERV

From Leibniz Research Laboratories for Biotechnology and Artificial Organs (LEBAO), ${ }^{\mathrm{a}}$ Medical School Hannover; National Research Center for Biotechnology, ${ }^{\mathrm{b}}$ Braunschweig; and the Department of Cardiothoracic and Vascular Surgery, ${ }^{c}$ Medical School Hannover, Hannover, Germany.

Copyright (C) 2001 by The American Association for Thoracic Surgery

0022-5223/2001 $\$ 35.00+0 \quad \mathbf{1 2 / 1 / 1 1 2 5 3 0}$

doi:10.1067/mtc.2001.112530 permanently integrated in the pig genome (PERV A and B) expressed in pig hearts, spleens, and kidneys and differing in their envelope proteins. ${ }^{5}$ Taken together, these findings strongly questioned the safety of xenografts. Nevertheless, at present there is no evidence 6 for crossspecies transmission of PERV in patients who have been treated with a multitude of living pig tissues, such as extracorporeal liver and kidney and splenic perfusion, bioartificial liver perfusion, pig skin grafts, and pancreatic islet cell transplants. However, most of these patients were exposed to porcine tissue only for a short time and not or only partially immunosuppressed. In contrast, in patients receiving xenotransplants, initially a high dose of immunosuppression and subsequent lifelong immunosuppression will be mandatory, thus facilitating possible PERV infection.

Until now, pretreated pig heart valves widely used for aortic valve replacement/mitral valve replacement (AVR/MVR) have been neglected as a possible source for transmission of PERV in human subjects. We therefore investigated the potential of pig heart valves to cause PERV infection in patients who underwent AVR/MVR. For this purpose, we explanted native 


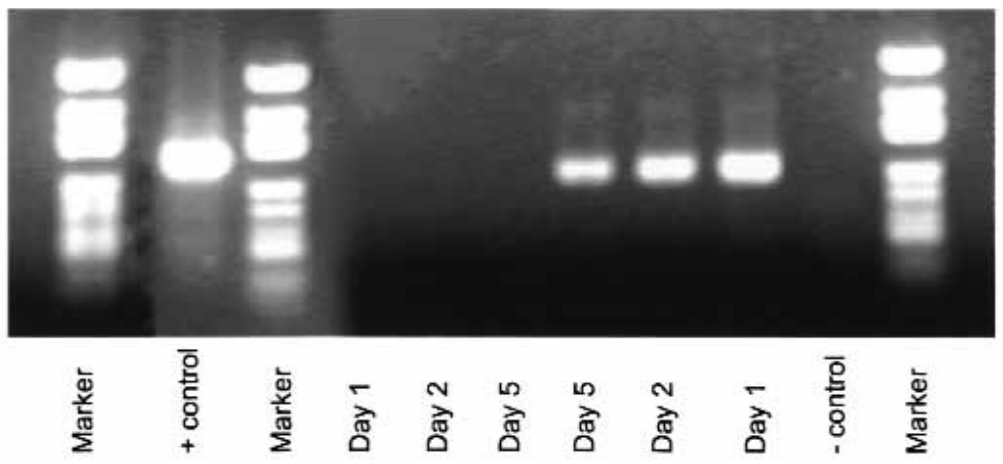

Fig 1. PCR of DNA of glutaraldehyde-fixed porcine heart valves. Lane 1, Marker; lane 2, positive control with PK 15 cells; lane 3, marker; lanes 4 to 6 , human vascular primary cells; lanes 7 to 9 , DNA of glutaraldehydefixed porcine heart valves; lane 10, negative control with human endothelial cells; lane 11, marker.

porcine heart valves that were analogous to commercially available valves fixated in $3 \%$ glutaraldehyde. We then assessed after which time period PERV was no longer detectable by means of polymerase chain reaction (PCR) and reverse transcription PCR (RT-PCR). Second, 3 commercially available porcine heart valves (Carpentier-Edwards, Baxter Healthcare Corp) used for AVR and MVR in human subjects were tested for PERV. Finally, blood samples from 18 patients ( 9 men and 9 women; age range, 71-86 years old; average age, 78.4 years) were collected 6 months to 3 years after AVR/MVR to investigate the possible expression of PERV DNA-RNA in lymphocytes and in plasma. Lymphocytes were isolated by means of density gradient centrifugation by using Ficoll-Paque reagents (Pharmacia Biotech, Uppsala, Sweden).

\section{Methods}

In vitro isolation of PBMCs from whole blood. FicollPaque gradient was prepared according to the manufacturer's instructions. Anticoagulant-treated blood was layered on the Ficoll-Paque solution and centrifuged at $400 \mathrm{~g}$ for 40 minutes at $20^{\circ} \mathrm{C}$. Differential migration during centrifugation results in the formation of layers containing different blood cell types. First, the upper layer of plasma was discarded. Then the lymphocyte layer was transferred to a clean centrifuge tube. Two washing steps followed, adding 3 volumes of balanced salt solution and centrifugation at $100 \mathrm{~g}$ for 10 minutes at $20^{\circ} \mathrm{C}$. The supernatant was removed, and the lymphocytes in pellets were homogenized in denaturing solution.

Isolation of DNA and total RNA of PBMCs and tissue. The cusps of one heart valve and Ficoll-Paque isolated PBMCs were homogenized in a denaturing solution containing $4 \mathrm{~mol} / \mathrm{L}$ guanidine thiocyanate, $25 \mathrm{mmol} / \mathrm{L}$ sodium citrate, $0.5 \% \mathrm{~N}$-lauroyl-sarcosine (Sarkosyl), and $0.1 \mathrm{~mol} / \mathrm{L} \mathrm{2-}$ mercaptoethanol. One milliliter of homogenate was mixed with $0.1 \mathrm{~mL}$ of $2 \mathrm{~mol} / \mathrm{L}$ sodium acetate $(\mathrm{pH} 4)$. After several inversions, $1 \mathrm{~mL}$ of water-saturated phenol was added and thoroughly mixed, and $0.2 \mathrm{~mL}$ of $49: 1$ chloroform/isoamyl alcohol was added. The suspension was incubated for 15 minutes at $4^{\circ} \mathrm{C}$. After centrifugation at $10,000 \mathrm{~g}$ for $20 \mathrm{~min}$ utes at $4{ }^{\circ} \mathrm{C}$ the aqueous RNA-containing phase was transferred in a second tube. The interphase and lower organic phase were used to precipitate DNA.

DNA. Per $1 \mathrm{~mL}$ of denaturing solution, $0.3 \mathrm{~mL}$ of $100 \%$ ethanol was added, incubated for 5 minutes at room temperature, and centrifuged at $2000 \mathrm{~g}$ for 5 minutes at $4^{\circ} \mathrm{C}$. Proteincontaining supernatant was removed, and the DNA pellet was washed twice in $0.1 \mathrm{~mol} / \mathrm{L}$ sodium citrate. The DNA pellet was resuspended in $75 \%$ ethanol and incubated for $20 \mathrm{~min}-$ utes at room temperature. The dried DNA pellet was dissolved in $8 \mathrm{mmol} / \mathrm{L} \mathrm{NaOH}$ and centrifuged at $12,000 \mathrm{~g}$ for 10 minutes. The supernatant was then transferred to a new tube, DNA was quantitated by reading the $\mathrm{A}_{260}$, and 0.5 to $1 \mu \mathrm{g}$ was added to the PCR mix.

RNA. RNA was precipitated by adding $1 \mathrm{~mL}$ of $100 \%$ isopropanol to the aqueous phase, incubating for 30 minutes at $-20^{\circ} \mathrm{C}$, and centrifuging at $10,000 \mathrm{~g}$ for 10 minutes at $4^{\circ} \mathrm{C}$. The RNA pellet was dissolved in $0.3 \mathrm{~mL}$ of denaturing solution and precipitated by adding $0.3 \mathrm{~mL}$ of $100 \%$ isopropanol, incubating for 30 minutes at $-20^{\circ} \mathrm{C}$, and centrifuging at $10,000 \mathrm{~g}$ for 10 minutes at $4^{\circ} \mathrm{C}$. The pellet was resuspended in $75 \%$ ethanol, mixed, and incubated for 15 minutes at room temperature and afterward centrifuged at $10,000 \mathrm{~g}$ for $5 \mathrm{~min}$ utes at $4{ }^{\circ} \mathrm{C}$. The supernatant was discarded, and the pellet was dried. RNA was dissolved in 100 to $200 \mu \mathrm{L}$ of diethyl pyrocarbonate-treated water, incubated for 15 minutes at $55^{\circ} \mathrm{C}$, and stored at $-70^{\circ} \mathrm{C}$. RNA was quantitated by reading the $\mathrm{A}_{260}$ and $\mathrm{A}_{280}$. One microgram was used for RT-PCR.

Isolation of DNA and total RNA from cell cultures. Cellular DNA and total RNA of 2 to $5 \times 10^{6}$ human cells and porcine cells out of cell culture were prepared by using TRI Reagent (Molecular Research Center, Inc, Cincinnati, Ohio) according to the manufacturer's instructions.

Potentially contaminating DNA in the total RNA preparation was digested by means of DNAse treatment (Boehringer Mannheim, Division of Roche Pharmaceuticals, Mannheim, Germany). For $10 \mu \mathrm{g}$, total RNA was $10 \mathrm{U}$ of RNAse-free DNAse I, $40 \mathrm{U} / \mu \mathrm{L}$ RNAse inhibitor (Boehringer Mannheim), 


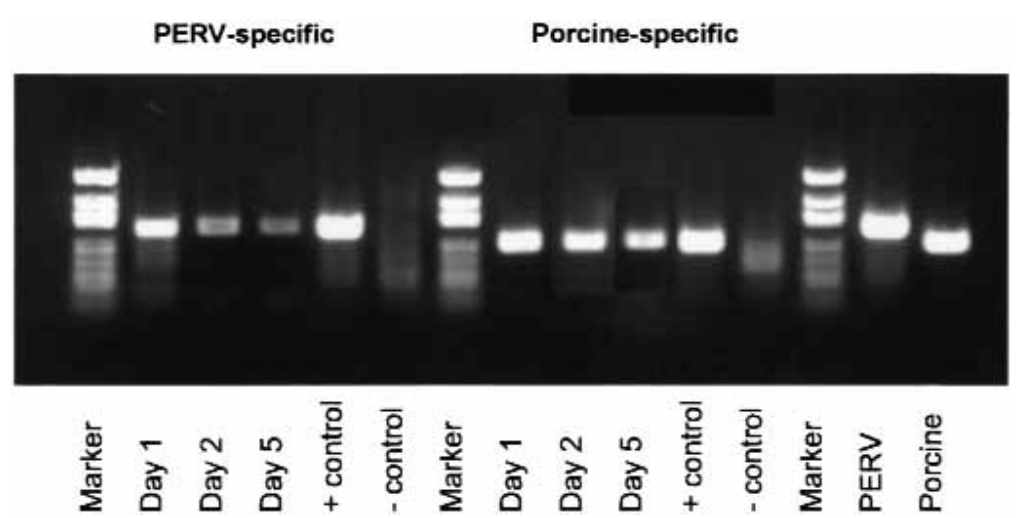

Fig 2. RT-PCR of RNA of glutaraldehyde-fixed porcine heart valves. Lane 1, Marker; lanes 2 to 6, RT-PCR with PERV-specific primers: RNA of glutaraldehyde-fixed native porcine heart valves (days 1, 2, and 5; lanes 2-4), positive control (PK 15, lane 4), and negative control (human endothelial cells, lane 5); lane 7, marker; lanes 8 to 12, RT-PCR with porcine-specific primer: RNA of glutaraldehyde-fixed native porcine heart valves (days 1, 2, and 5; lanes 8-10), positive control (PK 15, lane 11), and negative control (human endothelial cells, lane 12); lane 13, marker; lane 14, RT-PCR of RNA from PK 15 cells with PERV-specific primer; lane 15, RT-PCR of RNA from PK 15 cells with porcine-specific primer.

$1 \mathrm{~mol} / \mathrm{L} \mathrm{MgCl}_{2}$, and $0.1 \mathrm{~mol} / \mathrm{L}$ dithiothreitol used and incubated for 15 minutes at $37^{\circ} \mathrm{C}$, followed by a phenol-chloroform extraction.

Purification of viral RNA from plasma. For purification of viral RNA from human plasma, Qiagen QiAamp viral RNA Mini Kit (Qiagen GmbH, Hilden, Germany) was used. Viral RNA preparation was done according to the manufacturer's instructions.

PERV-specific PCR and RT-PCR. These methods were performed according to the PERV pol-specific PCR/RT-PCR of Patience, Takeuchi, and Weiss ${ }^{3}$ and porcine-specific RT-PCR of Heneine and associates. ${ }^{7}$ For cDNA synthesis, $1 \mu \mathrm{g}$ of total RNA and AMV-RT (Boehringer Mannheim) was used. PCR was done with $1 \mu \mathrm{g}$ of DNA. PCR products were separated on $2 \%$ agarose gel in an ethidium bromide-TAE buffer. The sensitivity of our PCR and RT-PCR averages 50 PERV copies in a total of 1 million RNA or DAN copies (data not shown).

Glutaraldehyde fixation of porcine heart valves. Twenty-two percent glutaraldehyde (Merck KGaA, Darmstadt, Germany) was diluted with phosphate-buffered saline solution to a final concentration of $3 \%$. Fresh isolated porcine heart valves with a part of the heart muscle and a part of the aorta were incubated in the $3 \%$ glutaraldehyde solution by $4{ }^{\circ} \mathrm{C}$. DNA and RNA of one cusp and $100 \mathrm{mg}$ of aortic tissue were isolated, as described previously.

\section{Results}

PERV sequences in glutaraldehyde-fixed native porcine heart valves. PERV sequences, DNA (Fig 1) and RNA (Fig 2), were clearly detectable 1 day after fixation of native porcine heart valves. After 5 days, there was only a weak signal for PERV RNA, but DNA remained detectable. In contrast, the intensity of porcine-specific signals did not decrease as fast (Fig 2).
PERV sequences in commercially available valves. Two cusps of one heart valve and half of the surrounding anulus from 3 different porcine heart valves were used to isolate RNA and DNA. Only a negligible amount of RNA could be isolated, indicating that glutaraldehyde fixation of the tissue is responsible for the entire degradation of RNA. The prepared porcine DNA was used in PERV pol-specific PCR, as shown in Fig 3. Although porcine DNA was detectable (lane 8), PERV-specific sequences were impossible to amplify (lane 2-7). In conclusion, our results indicate that commercial glutaraldehydefixed heart valves do not carry PERV DNA or at least not a detectable amount of endogenous retroviral sequences.

PERV sequences in patients after valve replacement. Porcine plasma, which was treated in the same manner as the 18 patient probes, served as a positive control. These controls constantly yielded a distinctive PERV-specific signal, whereas all patient samples remained negative up to 3 years after valve replacement (Fig 4).

Examination of PBMCs of patients after AVR/MVR by means of PCR revealed negative results in all 18 recipients (Fig 5). Positive controls (porcine PBMCs) uniformly showed a strong signal for PERV sequences. Plasma and PBMC probes from 4 young and healthy volunteers were obtained and served as negative controls.

Thus, up to 3 years after implantation of glutaraldehyde-fixed porcine heart valves, no cross-species transmission of PERV in human subjects occurred. 


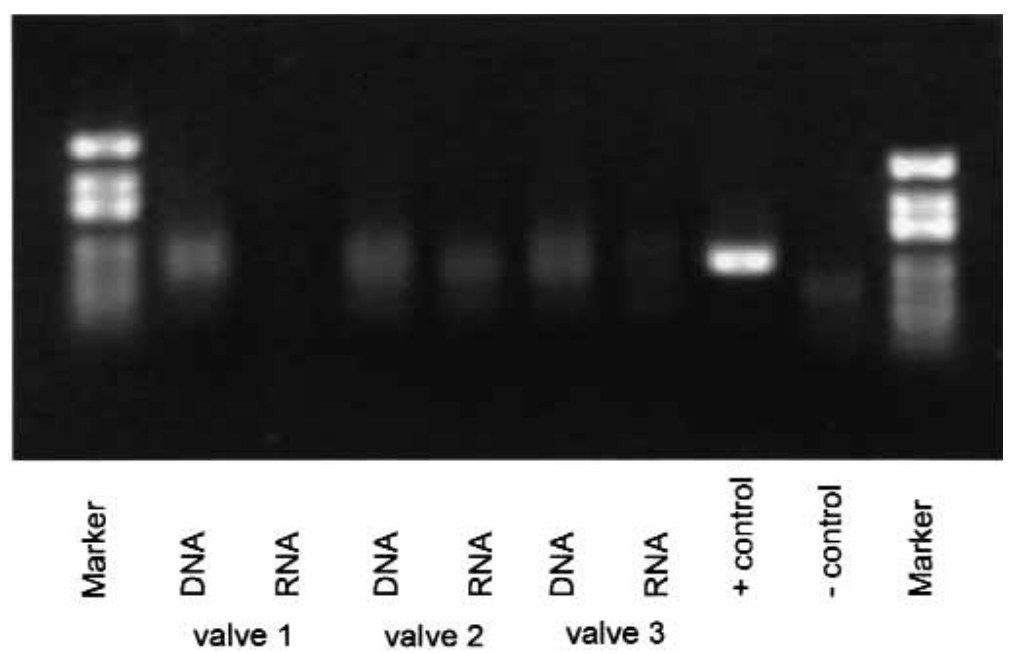

Fig 3. PERV sequences in 3 different commercially available heart valves. Lane 1, Marker; lanes 2 to 7 , PCR of DNA and RT-PCR of RNA from 3 different heart valves; lane 8, positive control (PCR of DNA from native porcine heart valve with porcine-specific primer); lane 9, negative control (PCR of DNA from native porcine heart valve with human-specific primer); lane 10, marker.

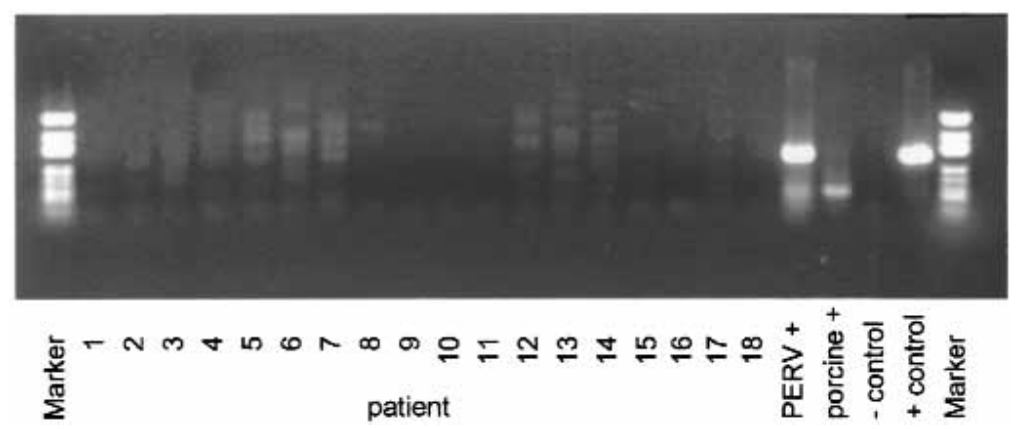

Fig 4. Plasma probes of patients after heart valve replacement. Lane 1, Marker; lanes 2 to 19, PCR of DNA from patient plasma probes with PERV-specific primers; lane 20, PCR of porcine plasma with PERV-specific primers; lane 21, PCR of porcine plasma with porcine-specific primers; lane 22, negative control (human endothelial cells with PERV-specific primer); lane 23, positive control (PK 15 with PERV-specific primer); lane 24 , marker.

\section{Discussion}

There are still major doubts about the safety of pig xenografts in terms of cross-species infection of human subjects with PERV ${ }^{2}$ enhanced by recent studies, demonstrating that PERV is capable of infecting human cell lines in vitro. ${ }^{3}$ However, this does not entirely reflect the situation in vivo. Patients who had been exposed, although predominantly only for a short period of time, to pig tissue in various clinical settings had negative test results for PERV. ${ }^{6}$ These data are only applicable with certain reservations to future transplantation of xenografts. First, the patients in this study were not immunosuppressed, which is still indispensable for a successful transplantation of organs in general. Second, Paradies and associates ${ }^{6}$ did not provide any data about patients who were treated for a relatively short period of time.

The use of porcine heart valves has become a routine procedure in cardiac operations. We now wanted to investigate whether we would be able to trace PERV in porcine heart valves commonly implanted in human subjects and whether patients who underwent AVR/MVR with biologic prostheses have been infected with PERV. 


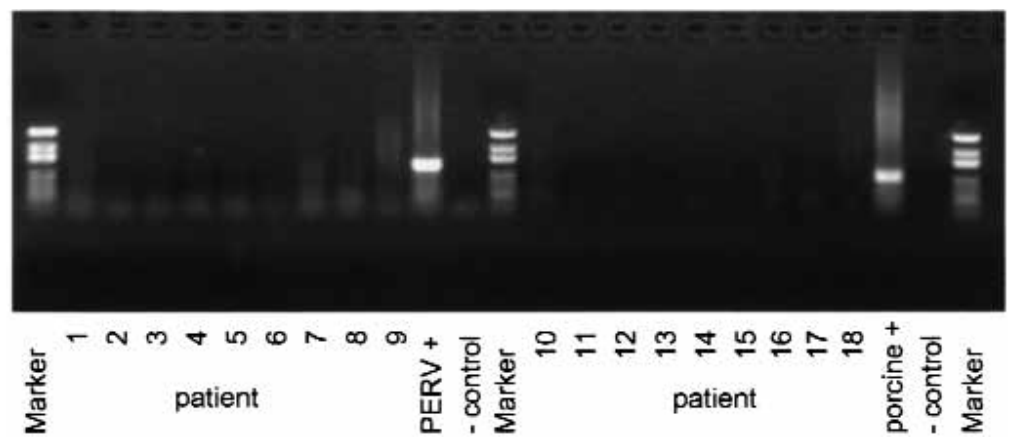

Fig 5. PCR of DNA from PBMCs in patients after heart valve replacement. Lane 1, Marker; lanes 2 to 10, PBMCs of patients 1 to 9; lane 11, positive control (porcine PBMCs with PERV-specific primers); lane 12, negative control (human PBMCs with PERV-specific primers); lane 13, marker; lanes 14 to 22, PBMCs of patients 10 to 18 ; lane 23, PCR of DNA from porcine PBMCs with porcine-specific primers; lane 24, PCR of DNA from human PBMCs with porcine-specific primers; lane 25, marker.

Our first step was to examine glutaraldehyde-fixed native porcine heart valves to assess the degrading time of PERV RNA-DNA. As we have shown, traces of PERV RNA-DNA are only detectable within the first week after glutaraldehyde fixation. These results already indicated that glutaraldehyde-fixed porcine heart valves carry a low risk of interspecies PERV transmission. To verify this assumption, we extracted DNA and RNA of commercially available heart valves usually implanted in human subjects. According to our PCR and RT-PCR results, no fragments of PERV sequences were detectable, making further transmission of PERV from porcine heart valves unlikely.

Taken together, these results reveal fragments of PERV sequences to completely degrade in glutaraldehyde-fixed porcine heart valves within 1 week. Therefore, it is not surprising that we were unable to trace PERV DNA-RNA in commercially available biologic heart valves, which were originally destined for clinical use.

Nevertheless, one cannot exclude transmission of PERV to human subjects if porcine glutaraldehydefixed valves are implanted because porcine cells containing endogenous retrovirus remain present in the graft. Despite this low probability, we examined blood samples of patients after AVR/MVR with biologic heart valves. We failed to detect PERV DNA-RNA isolated from lymphocytes and plasma of patients who underwent AVR/MVR with porcine heart valves. In these patients, cardiac operations have been performed 6 months to 3 years before examination, providing enough time for possible PERV infection to occur.

In conclusion, we were not able to trace PERV transmission or infection in patients who underwent valve replacement with porcine heart valve prostheses nor could we detect PERV in porcine heart valves commonly used in human subjects. From our results, fixation of porcine heart valves in glutaraldehyde, as used commercially, is entirely sufficient to prevent interspecies transmission of PERV.

Received for publication June 8, 2000; revisions requested Aug 11, 2000; revisions received Sept 18, 2000; accepted for publication Oct 25, 2000.

Address for reprints: Ajay Kumar Moza, Medical School Hannover, Division of Cardio-Thoracic and Vascular Surgery, Carl-Neuberg-Str. 1, D-30625 Hannover, Germany (E-mail: moza@thg.mh-hannover.de).

\section{REFERENCES}

1. Animal to human transplants: the ethics of xenotransplantation. London: Nuffield Council on Bioethics; 1996.

2. Weiss RA. Transgenic pigs and virus adaption. Nature 1988;391:327-8

3. Patience $C$, Takeuchi Y, Weiss RA. Infection of human cells by an endogenous retrovirus of pigs. Nat Med 1997;3:282-6.

4. Wilson CA, Wong S, Muller J, Davidson CE, Rose TM, Burd P. Type $\mathrm{C}$ retrovirus released from porcine primary peripheral blood mononuclear cells infects human cells. J Virol 1998;72:3082-7.

5. Martin U, Kiessig V, Blusch JH, Haverich A, von der Helm K, Herden T, et al. Expression of pig endogenous retrovirus by primary porcine endothelial cells and infection of human cells. Lancet 1998;352:692-4.

6. Paradies K, Langford G, Long Z, Heneine W, Sandstrom P, Switzer WM, et al. Search for cross-species transmission of porcine endogenous retrovirus in patients treated with living pig tissue. Science 1999;285:3082-7.

7. Heneine W, Tibell A, Switzer WM, Sandstrom P, Rosales GV, Mathews A, et al. No evidence of infection with porcine endogenous retrovirus in recipients of islet-cell xenografts. Lancet 1998;352:695-9. 